\title{
Models of speed development in soccer
}

\author{
Authors' Contribution: \\ A Study Design \\ B Data Collection \\ C Statistical Analysis \\ D Data Interpretation \\ E Manuscript Preparation \\ F Literature Search \\ G Funds Collection
}

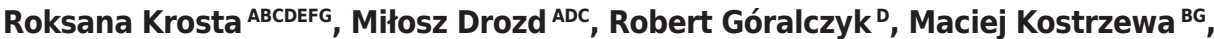 Patricia Fischerova ${ }^{\mathrm{BC}}$, Angelina Ignatieva ${ }^{\mathrm{BC}}$}

The Jerzy Kukuczka Academy of Physical Education in Katowice, Poland

\section{abstract}

Background: The main objective of this research was to determine a model of the Speed Abilities Development Index (SADI) in selected teams of the top league, the first and the second league in Poland. The indirect aim was to determine the most significant predictors that have the greatest effect on development of this model.

Material and methods: The study examined a group of randomly selected 20 athletes (age $24 \pm 3$ years) from four Polish premium league soccer teams, four teams of the first league and four teams of the second league, what amounted to 60 randomly selected players. The following independent variables related to starting and absolute running were considered: $5 \mathrm{~m}, 20 \mathrm{~m}, 30 \mathrm{~m}, 520 \mathrm{~m}, 530 \mathrm{~m}, 2030 \mathrm{~m}$.

Results: In the group of top league players the model determined the following predictors of speed as most significant: the sprint time of 5 to $30 \mathrm{~m}$ segment run, the sprint time recorded between 20 to $30 \mathrm{~m}$ and the mean result of the RAST. In the group of players from the first and second leagues, the predictors included: the time of 20 to $30 \mathrm{~m}$ run, mean result of the RAST and the sprint time of the $5 \mathrm{~m}$ run.

Conclusions: A good soccer player should be prepared for both short ( 5 to $20 \mathrm{~m}$ ) and longer ( 30 to $50 \mathrm{~m}$ ) runs at the highest speed possible.

Key words: soccer, speed, regression model, motor abilities, motor potential.

\section{article details}

Article statistics: Word count: 2,710; Tables: 6; Figures: 0; References: 21

Received: April 2020; Accepted: May 2020; Published: June 2020

Full-text PDF: http://www.balticsportscience.com

Copyright @ Gdansk University of Physical Education and Sport, Poland

Indexation: Celdes, Clarivate Analytics Emerging Sources Citation Index (ESCl), CNKI Scholar (China National Knowledge Infrastructure), CNPIEC, De Gruyter - IBR (International Bibliography of Reviews of Scholarly Literature in the Humanities and Social Sciences), De Gruyter - IBZ (International Bibliography of Periodical Literature in the Humanities and Social Sciences), DOAJ, EBSCO - Central \& Eastern European Academic Source, EBSCO - SPORTDiscus, EBSCO Discovery Service, Google Scholar, Index Copernicus, J-Gate, Naviga (Softweco, Primo Central (ExLibris), ProQuest - Family Health, ProQuest - Health \& Medical Complete, ProQuest - Illustrata: Health Sciences, ProQuest - Nursing \& Allied Health Source, Summon (Serials Solutions/ProQuest, TDOne (TDNet), Ulrich's Periodicals Directory/ulrichsweb, WorldCat (OCLC)

Funding: The research is funded by grants of Ministry of Science and Higher Education of Poland (NRSA3 03953 and NRSA4 040 54).

Conflict of interests: Corresponding author:

Open Access License: Authors have declared that no competing interest exists.

The Jerzy Kukuczka Academy of Physical Education, Department of Sports Theory, Sports Training Facility, Head of the Hypoxia laboratory, Mikołowska 72A str., 40-065 Katowice, Poland; 603966719; e-mail: m.drozd@awf.katowice.pl

This is an open access article distributed under the terms of the Creative Commons Attribution-Non-commercial 4.0 International (http://creativecommons.org/licenses/by-nc/4.0/), which permits use, distribution, and reproduction in any medium, provided the original work is properly cited, the use is non-commercial and is otherwise in compliance with the license. 


\section{INTRODUCTION}

Due to its popularity, simplicity of the game, variability of situations and high dynamics, soccer has been the focus of numerous studies. A key issue in this sport is not only tactics but also adequate motor preparation of a player that ensures performance of the tactical tasks.

Analysis of the history of soccer reveals substantial changes in playing styles. Recent years have seen an increase in its speed and changes in the competitive strategies. Consequently, the methodology of soccer playing looks quite different than it used to several years ago and the attempts are being made to maximize motor potential of a player, which involves the use of more effective technical skills in competitive conditions, especially among elite players.

Running speed is a factor that determines the potential of the body to cover a distance as fast as possible. It is consists of three components: reaction speed, movement speed and frequency of movements [1]. The level of these components has a direct impact on the player's effectiveness during the game. Therefore, [2] indicate that the new training concepts in soccer subordinate endurance training to speed and strength conditioning. Sprints often start when the player is moving at a slower speed, also while the player performs numerous changes of direction, characteristic of soccer. Individual running actions often begin, when a player is running to his position or when marking a player from the opposing team. There is also much fighting for the ball in the air. Therefore, it should be emphasized that playing performance in soccer is to a large degree dependent on the ability to accelerate over the first few steps.

Depending on the country and the league particular authors report a different mean distance covered by sprint during a soccer match: it ranges from 215 to $446 \mathrm{~m}$ [3], 199 to $290 \mathrm{~m}$ [4], 179 to $334 \mathrm{~m} \mathrm{[5],} \mathrm{or} 193$ to $260 \mathrm{~m}$ (Spanish league), 208 to 278 m (English league), 167 to 345m (European league) [6].

Ferro found that the use of specific training methods and modern concepts of periodization may lead to an improvement in different components of speed such as: acceleration, absolute speed and speed endurance, which increase a player'scompetitive value [1].

Speed, which is a complex motor ability, plays a more significant role in contemporary soccer. In a soccer match, speed manifests itself as a complex psychophysical ability to utilize specific technical and tactical skills most effectively and most dynamically under the pressure of opponents and time.

Speed comprises motor and cognitive components, which are closely related in functional terms. The speed of the motor component is controlled by neurophysiological processes (jumping, acceleration, changes in running direction, dynamic cuts, starting speed). The main role of the cognitive component is played by the analytical and decision centres of the cerebral cortex, which receives and processes information (choice of activity, speed of making proper decisions, speed of reaction, speed of perception and prediction). The process of processing and receiving information in the cerebral cortex is invisible: the only visible element is the motion itself and the speed at which the movement is performed. The speed of particular actions during a match depends not only on the players' running speed, but also on their psychomotor aptitude. For instance, delayed perception and assessment of a match situation results in 
wrong decisions and choosing inappropriate actions. Therefore, performing a fast but improper movement during the match is ineffective. Before a player runs to the ball, he should analyse the situation and make a certain decision. Without proper analysis, even a fast player cannot utilize this ability, particularly in tight spaces, and under opponents' and time pressure, where an unconventional dummy should be used immediately combined with a change in direction of running, or a dynamic individual action should be performed, completed with an unexpected shot to the goal, a precise pass or cross to a teammate. Players of lower sports levels often move to the open space too quickly or too slowly, and they also cannot utilize the advantage of greater number of players in situations of $2: 1,3: 1$ or $3: 2$. This is caused by erroneous assessment of the situation, which leads to wrong decisions and improper choice of actions. During dynamic actions with or without the ball, players are constantly preoccupied by the assessment of the direction and speed of the ball, as well as the movement of players from their own and the opposing team. Under such situations, the main role is played by cognitive processes, which does not mean that the speed of movement is less important and should not be developed. On the contrary, it should be properly and regularly improved as it represents the most basic motor ability responsible for the effectiveness of a player on the field [7].

Unlike such abilities as endurance or muscular strength, speed is largely determined genetically. Therefore, substantial improvements in speed are significantly related to the player's genotype. Accordingly, even long-term and intensive training may not bring improvements in speed. Speed abilities are closely linked to such genetic determinants as high content of fast twitch fibres (type IIx white fibres), ability to excite them selectively, efficiency of nervous processes, especially the ability to switch from excitation to inhibition, which determines the frequency of movements [8]. However, speed is only one of the motor components that determine sports performance in soccer. Beside motor abilities, technical and tactical skills are of great importance in soccer and other team sport games.

This study concentrates only on one aspect of soccer performance, which is running speed. The main objective of this research was to determine a model of the Speed Abilities Development Index (SADI) in selected teams of the top league, the first and the second league in Poland. The second indirect aim was to determine the most important predictors that have the biggest effect on development of this index. 


\section{MATERIAL AND METHODS}

\section{PARTICIPANTS}

We examined a group of randomly selected 60 athletes (age: $24 \pm 3$ years) from four Polish top-level league teams, four teams of the first league and four teams of the second league. All the measurements were performed in an indoor sports facility. Temperature in the gyms ranged from $22^{\circ} \mathrm{C}$ to $24^{\circ} \mathrm{C}$. The measurements were taken in the morning, from 8:00 to 11:00 a.m. A standard 25-minute warm-up was used before the tests, including running and dynamic stretching exercises. Measurements were made in February, March, and April. The best results were used for further analysis.

\section{TESTS AND MEASUREMENT METHODOLOGIES}

The RAST test was used in the study. The test was modified to 6 sprints over 30-m with 25-s rest intervals. The measurements used four photocell systems installed at consecutive distances of the 30-meter distance: $0 \mathrm{~m}$ (start), $5 \mathrm{~m}, 20 \mathrm{~m}$ and $30 \mathrm{~m}$.

Each player was also tested for the maximal running speed, which we used for diagnosis of the players' speed potential. A set of photocell systems installed at $0 \mathrm{~m}, 5 \mathrm{~m}, 20 \mathrm{~m}, 30 \mathrm{~m}$ was used during the measurements. Reaction time of the study participants was not taken into account since photocells were released automatically at the instant the study participant crossed the starting line. Split times were also measured at the distances between the photocells.

The following independent variables were obtained from the measurements: times at $5 \mathrm{~m}, 20 \mathrm{~m}, 30 \mathrm{~m}$, between $520 \mathrm{~m}$, between $530 \mathrm{~m}$, and between 20-30 m. Seven independent variables were determined in total.

\section{STATISTICAL ANALYSIS}

In order to solve the research problem considered in this study, we used empirical analysis, a prognostic survey and exploration examinations of an experimental character. The methodologies of model econometrics were used [9]. The initial number of variables was determined based on the contextual analysis. Since the number of variables was high, it was necessary to use an adequate statistical algorithm to obtain the optimal subset. The results of numerous analyses [10-14] have shown that the most effective procedure of optimal choice of the independent variables is the method of determination of the R0 and R1 vectors using the analysis of the matrix of correlation coefficients. This method was used to determine an optimal vector of independent variables. Accordingly, the optimal subset of independent variables that was used for building the biometric model was composed of six variables: sprint times at $5 \mathrm{~m}, 20 \mathrm{~m}, 30 \mathrm{~m}, 530 \mathrm{~m}, 20-30 \mathrm{~m}$ and mean RAST.

The major focus of this study was to determine the Speed Abilities Development Index (SADI) for three best soccer leagues based on the analysed stimulants and destimulants for each studied athleteand to obtain the dependent variable for building regression models $[9,15,16]$.

The Speed Abilities Development Index was determined as a dependent variable Y (SADI) using independent variables (stimulants and destimulants) according to the following formula: 


$$
\mathrm{u}_{(\mathrm{ij})}=\mathrm{x}_{(\mathrm{ij})}-\mathrm{Sr} \mathrm{x}_{(\mathrm{j})} / \mathrm{S}_{(\mathrm{Xj})}
$$

Where:

$\mathrm{x}_{\mathrm{j}}$ - stimulant variable

$\mathrm{x}_{\mathrm{i}}$ - destimulant variable

Furthermore, all the variables were standardized. The distances from the pattern were determined from the equation:

$$
c_{i}=\sqrt{\sum_{j=1}^{k}\left(u_{i j}-u_{j}\right)^{2}}
$$

This allowed obtaining a taxonomic measure of development (SADI) using the formula:

$$
\mathrm{SADI}_{i}=1-\frac{c_{i}}{\bar{c}+2 S(c)}
$$

The independent variables determined in the study using the matrix of correlation coefficients and vectors R0 and R1 were also used as input data for the regression model (stepwise regression) which was aimed to explicate the set of variables that has the major effect on the dependent variable Y SADI assigned to individual leagues (as Y1-Y3) and expressed as a regression function.

Analyses were based on the Excel 2010 software from Microsoft Office 2010 PL package and Statistica 8.0 package (Statsoft 2013).

\section{RESULTS}

The following results were obtained for the elite soccer teams during the speed tests. The descriptive statistics of all analysed variables for top, first and second leagues are presented in Tables 1-3.

Table 1. Descriptive statistics of variables that characterize the group of the top league players

\begin{tabular}{lccccc} 
Variable & N valid & Mean & SD & Skewness & Kurtosis \\
\hline Best $5 \mathrm{~m}$ & 20 & 1.022 & 0.022 & -0.113 & -0.942 \\
Best $20 \mathrm{~m}$ & 20 & 2.988 & 0.068 & -0.215 & -0.145 \\
Best $30 \mathrm{~m}$ & 20 & 4.148 & 0.097 & -0.605 & -0.386 \\
Best $530 \mathrm{~m}$ & 20 & 3.112 & 0.088 & -0.645 & -0.421 \\
Best 20-30 m & 20 & 1.155 & 0.037 & -0.949 & 0.696 \\
Mean RAST & 20 & 4.347 & 0.077 & 0.150 & -0.592 \\
\hline
\end{tabular}

Table 2. Descriptive statistics of variables that characterize the group of the first league players

\begin{tabular}{lccccc} 
Variable & N valid & Mean & SD & Skewness & Kurtosis \\
\hline Best $5 \mathrm{~m}$ & 20 & 1.073 & 0.048 & 0.890 & 0.606 \\
Best $20 \mathrm{~m}$ & 20 & 3.077 & 0.088 & -0.171 & -0.982 \\
Best $30 \mathrm{~m}$ & 20 & 4.206 & 0.184 & -1.577 & 3.960 \\
Best $530 \mathrm{~m}$ & 20 & 2.934 & 0.642 & -1.798 & 3.707 \\
Best 20-30 m & 20 & 1.364 & 0.582 & 1.873 & 2.008 \\
Mean RAST & 20 & 4.434 & 0.155 & 1.189 & 1.753 \\
\hline
\end{tabular}


Table 3. Descriptive statistics of sprint variables of the second league players

\begin{tabular}{lccccc} 
Variable & N valid & Mean & SD & Skewness & Kurtosis \\
\hline Best $5 \mathrm{~m}$ & 20 & 1.070 & 0.060 & 0.766 & 0.892 \\
Best $20 \mathrm{~m}$ & 20 & 3.084 & 0.116 & 0.416 & 0.178 \\
Best $30 \mathrm{~m}$ & 20 & 4.273 & 0.165 & 0.070 & -0.085 \\
Best $530 \mathrm{~m}$ & 20 & 3.174 & 0.106 & -0.114 & -0.165 \\
Best 20-30 m & 20 & 1.464 & 3.12 & 0.130 & 1.873 \\
Mean RAST & 20 & 4.443 & 0.157 & 0.032 & -0.024 \\
\hline
\end{tabular}

In the groups of elite players, the regression model determined the following predictors of speed as the most important: the best time of 5 to $30 \mathrm{~m}$ run, the best time of 20 to $30 \mathrm{~m}$ run and mean result of the RAST (Table 4).

In the group of the players from the first and second leagues, the predictors were: sprint time between 20 and $30 \mathrm{~m}$, mean result of the RAST and the time of $5 \mathrm{~m}$ sprint (respectively Tables 5-6).

Table 4. Regression model of predictors of speed abilities in the group of top league players for Y - SADI (Y1)

\begin{tabular}{lccc} 
& BETA & B & p level \\
\hline & & 1.102679 & 0.000019 \\
Best 5-30 m & -3.06233 & -0.476387 & 0.010337 \\
Mean Rast & -0.50109 & -0.088810 & 0.036864 \\
Best 20-30 m & -1.83812 & -0.673491 & 0.031928 \\
\hline
\end{tabular}

Note: $\mathrm{R}=.92154967 \mathrm{R} \wedge 2=.902063393 ;$ Adjusted R2 = .89943176; F(5.14) = $3.0410 \mathrm{p}<.04595$;

Standard error of estimation: .01108

Table 5. Regression model of predictors of speed abilities in the first league

\begin{tabular}{lccc} 
& BETA & B & p level \\
\hline & & 0.864598 & 0.00100 \\
Best 20-30 m & -0.985571 & -0.114649 & 0.001 \\
Mean Rast & -0.078636 & -0.034380 & 0.001 \\
Best 5 m & -0.009862 & -0.013899 & 0.031 \\
\hline
\end{tabular}

Note: $\mathrm{R}=.99972525 \mathrm{R}^{\wedge} 2=.99945058 ;$ Adjusted $\mathrm{R} 2=.99934756 ; \mathrm{F}(3.16)=9701.9 \mathrm{p}<0.0000$;

Standard error of estimation: .00173

Table 6. Regression model of predictors of speed abilities in the second league

\begin{tabular}{lccc} 
& BETA & B & p level \\
\hline & & 0.864883 & 0.001 \\
Best 20-30 m & -1.41376 & -0.116014 & 0.001 \\
Mean Rast & -1.06811 & -0.031599 & 0.001 \\
Best 5 m & -0.01421 & -0.001086 & 0.043 \\
\hline
\end{tabular}

Note: $\mathrm{R}=.99956581 \mathrm{R}^{\wedge} 2=.99913180 ;$ Adjusted $\mathrm{R} 2=.99986902 ; \mathrm{F}(3.16)=6137.7 \mathrm{p}<0.0000$;

Standard error of estimation: .00015

Analysis of regression revealed the following models for Y1 (Top league), Y2 (first league) and Y3 (second league):

SADI $(Y 1)=1.103-0.476$ best5-30m - 0,673best 20-30m - 0.088meanRast \pm 0.174

SADI $(Y 2)=0.864-0.115$ best 20-30m- 0.034meanRast -0.014 best5m $\pm 0,011$

SADI $(\mathrm{Y} 3)=0.865-0.116$ best20-30m -0.032 meanRast -0.001 best5m \pm 0.009 


\section{DISCUSSION}

Modelling of variables with consideration for the SADI index as a dependent variable allowed for determination of the most important predictors of speed abilities.

In the groups of top league players, the first and the second leagues, the regression model determined three predictors for Speed Abilities Development Index (SADI). In order to determine the SADI indices of individual classes of particular leagues, the same correlations of variables $2030 \mathrm{~m}$ sprint, RAST, and the $5 \mathrm{~m}$ sprint start were used apart from one case in the SADI index for the top league with the variable $530 \mathrm{~m}$ sprint included.

The obtained data confirmed the previously presented results, pointing to the fact that the competition at the highest national level is more dynamic, and the athletes are characterized by better speed abilities. It is known that $90 \%$ of the energy supply in a soccer game comes from the aerobic system, yet it is anaerobic efforts, especially explosive activities lasting several seconds, which determine success in this sports discipline.

Furthermore, as suggested by Bottinelli et al. [17] and Idrizowić et al. [18], soccer is a game with great physical fitness demands. A good soccer player should be prepared for both short ( 5 to $20 \mathrm{~m}$ ) and longer (30 to $50 \mathrm{~m}$ ) runs at the highest speed possible (instantaneous accelerations from 9 to $10 \mathrm{~m} / \mathrm{s}$ ).

Apart from speed, the results of $5 \mathrm{~m}$ sprint starts provide feedback for coaches that help develop specific strength abilities in soccer players. The results of 20 and $30 \mathrm{~m}$ runs are considered as speed indicators, whereas additional measurements at flying start distances of $520 \mathrm{~m}$ and $2030 \mathrm{~m}$ reflect the athletes' coordination and inherited speed abilities. The results of this test can inform the athletes and coaches about the strengths and weaknesses in specific physical fitness characteristics. The obtained results can be very informative, and used for annual monitoring of speed abilities. An athlete can compare his results to previous ones and to his personal best. He can also be evaluated in comparison to the whole team. Furthermore, the test may be used as a reliable measure of the athlete's fitness after a rehabilitation program following an injury [19].

An insufficient development of speed in soccer players can be linked to inadequate knowledge and training of coaches, which prevents them from implementation of new training methodologies. As suggested, the problem lies in training methodologies used by Polish teams, especially those from lower leagues, where the training loads do not resemble game-specific exercises; they do not offer variability of intensity, volume and active rest. Another training mistake may lie in a lack of individual training loads [20].

Compared to the athletes from the highest league in Brazil, where the mean 30 $\mathrm{m}$ sprint times equal $7.68 \mathrm{~m} / \mathrm{s}$, players from Polish leagues reached significantly lower running speeds during a game (top league: $7.23 \mathrm{~m} / \mathrm{s}$, the first league $7.14 \mathrm{~m} / \mathrm{s}$, the second league $7.02 \mathrm{~m} / \mathrm{s}$ ) [21].

\section{CONCLUSIONS}

In conclusion, insignificant variation of particular speed abilities of players from Polish top league, first league and second league suggests that changes in training periodization are needed to ensure a more effective development 
of motor abilities among soccer players. Furthermore, this may not only substantially contribute to improvement results obtained by Polish teams but also, compared to the measurements of speed abilities among foreign teams (especially those playing in European cup competitions), indicate the effectiveness of these activities and improve the players. The national leagues would therefore improve level compared to what is observed today.

\section{REFERENCES}

[1] Ferro A, Villacieros J, Floría P, Graupera S. Analysis of speed performance in soccer by a playing position and a sports level using a laser system. J Hum Kinet. 2014;44:143153. https://doi.org/10.2478/ hukin-2014-0120

[2] Shady A, Mohammad A. Effect of spatial orientation and motor rhythm trainings on motor speed and skill performance level of soccer juniors. Ovidius University Annals, Series Physical Education \& Sport/Science. Movement \& Health. 2013;139(2):66-72.

[3] Amelia FS, Pablo F, Jorge V, Jose LG. Analysis of speed performance in soccer by a playing position and a sports level using a laser system. J Hum Kinet. 2014;44:129-137.

[4] Dellal A, Chamari K, Wong De P, Amaidi S, Keller D, Barros R. Comparison of physical and technical performance in European soccer match-play: FA Premier League and La Liga. Eur J Sport Sci Eur. 2011;11(1):5159. https://doi.org/10.1080/17461391.2010.481334

[5] Lago C, Casais L, Dominguez E, Sampaio J. The effects of situational variables on distance covered at various speeds in elite soccer. Eur J Sport Sci. 2010;10(2):103107. https://doi.org/10.1080/17461390903273994

[6] Bajramović I, Manić G, Alić H, Jelesković E. Differences in explosive strength sprinting for football players classified according to different positions in the field. Homo Sporticus. 2013;14(2):154.

[7] Marko J, Joksimović A, Kocić M, Nikolić D, Došić A. The differences between jump performance and speed of young football players with different levels of competition. Res Phys Educ Sport Health. 2014;3(2):3539.

[8] Andrzejewski M. Chmura J, Pluta B, Kasprzak A. Analysis of motor activities of professional soccer players. J Strength Cond Res. 2012;26(6):144148. https://doi.org/10.1519/JSC.0b013e318231ab4c

[9] Maestas C, Preuhs RR. Modeling volatility in political time series. Electoral Studies. 2000;19(1):95110. https://doi.org/10.1016/S0261-3794(99)00038-4

[10] Maszczyk A, Roczniok R, Czuba M, et al. Application of regression and neural models to predict competitive swimming performance. Perceptual \& Motor Skills. 2012;114(2):610624. https://doi.org/10.2466/05.10. PMS.114.2.610-626

[11] Maszczyk A, Zając A, Ryguła I. A Neural Network model approach to athlete selection. Sport Eng. 2011;13:8393. https://doi.org/10.1007/s12283-010-0055-y

[12] Maszczyk A, Gołaś A, Pietraszewski P, Roczniok R, Zając A, Stanula A. Application of neural and regression models in sports results prediction. Procedia Soc Behav Sci. 2013;117:482-487. https://doi. org/10.1016/j.sbspro.2014.02.249

[13] Roczniok R, Maszczyk A, Czuba M, Stanula A, Pietraszewski P, Gabryś T. The predictive value of on-ice special tests in relation to various indexes of aerobic and anaerobic capacity in ice hockey players. Hum Movement Sci. 2012;13(1):2836. https://doi.org/10.2478/v10038-012-0001-x

[14] Roczniok R, Ryguła I, Kwaśniewska A. The use of Kohonen’s Neural Networks in the recruitment process for sport swimming. J Hum Kinet. 2007;17:7588.

[15] Greene W. Econometric analysis. New Jersey: Prentice Hall; 2003.

[16] Keele L, Nathan JK. Dynamic models for dynamic theories: the ins and outs of lagged dependent variables. Political Analysis. 2006;14:186-205. https://doi.org/10.1093/pan/mpj006

[17] Bottinelli S, Schiaffinp C, Reggiani. Force-velocity relations and myosin heavy chain isoform compositions of skinned fibres from rat skeletal muscle. J Physiol. 1991;437:655-672. https://doi.org/10.1113/ jphysiol.1991.sp018617

[18] Idrizović K, Raičković N. The correlation between aerobic power, acceleration, repeated-sprint and speed endurance in elite female football. Sport \& Health. 2013;2(2):5156.

[19] Cometti G, Maffiuletti NA, Pousson M, Chatard JC, Maffulli N. Isokinetic strength and anaerobic power of lit, sub-elite and amateur French soccer players. Int J Sports Med. 2001;22:45-51. https://doi.org/10.1055/s-2001-11331

[20] Konefał M, Chmura P, Andrzejewski M, Chmura J. Analysis of motor performance of professional soccer players in different environmental conditions. Trends Sport Sci. 2014;4(21):221227.

[21] Coelho DB, Mortimer L, Condessa L, Morandi R, Oliveira B, Marins J. Intensity of real competitive soccer matches and differences among player positions. Rev Bras Cineantropom Desempenho Hum. 2011;13(5):94147. https://doi.org/10.5007/1980-0037.2011v13n5p341 